\title{
Strengthening insights into host responses to mastitis infection in ruminants by combining heterogeneous microarray data sources
}

Sem Genini ${ }^{1,15^{*}+}$, Bouabid Badaoui ${ }^{1 \dagger}$, Gert Sclep ${ }^{1 \dagger}$, Stephen C Bishop ${ }^{2}$, Dave Waddington ${ }^{2}$, Marie-Hélène Pinard van der Laan $^{3}$, Christophe Klopp ${ }^{4}$, Cédric Cabau ${ }^{5}$, Hans-Martin Seyfert ${ }^{6}$, Wolfram Petzl ${ }^{7}$, Kirsty Jensen², Elizabeth J Glass ${ }^{2}$, Astrid de Greeff ${ }^{8}$, Hilde E Smith ${ }^{8}$, Mari A Smits ${ }^{9}$, Ingrid Olsaker ${ }^{10}$, Guro M Boman ${ }^{10}$, Giuliano Pisoni ${ }^{11}$, Paolo Moroni ${ }^{11,16}$, Bianca Castiglioni ${ }^{12}$, Paola Cremonesi ${ }^{12}$, Marcello Del Corvo ${ }^{1,12}$, Eliane Foulon ${ }^{13}$, Gilles Foucras ${ }^{13}$, Rachel Rupp ${ }^{14}$ and Elisabetta Giuffra ${ }^{1,17}$

\begin{abstract}
Background: Gene expression profiling studies of mastitis in ruminants have provided key but fragmented knowledge for the understanding of the disease. A systematic combination of different expression profiling studies via meta-analysis techniques has the potential to test the extensibility of conclusions based on single studies. Using the program Pointillist, we performed meta-analysis of transcription-profiling data from six independent studies of infections with mammary gland pathogens, including samples from cattle challenged in vivo with S. aureus, E. coli, and S. uberis, samples from goats challenged in vivo with S. aureus, as well as cattle macrophages and ovine dendritic cells infected in vitro with S. aureus. We combined different time points from those studies, testing different responses to mastitis infection: overall (common signature), early stage, late stage, and cattle-specific.

Results: Ingenuity Pathway Analysis of affected genes showed that the four meta-analysis combinations share biological functions and pathways (e.g. protein ubiquitination and polyamine regulation) which are intrinsic to the general disease response. In the overall response, pathways related to immune response and inflammation, as well as biological functions related to lipid metabolism were altered. This latter observation is consistent with the milk fat content depression commonly observed during mastitis infection. Complementarities between early and late stage responses were found, with a prominence of metabolic and stress signals in the early stage and of the immune response related to the lipid metabolism in the late stage; both mechanisms apparently modulated by few genes, including XBP1 and SREBF1.

The cattle-specific response was characterized by alteration of the immune response and by modification of lipid metabolism. Comparison of E. coli and S. aureus infections in cattle in vivo revealed that affected genes showing opposite regulation had the same altered biological functions and provided evidence that $E$. coli caused a stronger host response.

Conclusions: This meta-analysis approach reinforces previous findings but also reveals several novel themes, including the involvement of genes, biological functions, and pathways that were not identified in individual studies. As such, it provides an interesting proof of principle for future studies combining information from diverse heterogeneous sources.
\end{abstract}

Keywords: Meta-analysis microarray analysis, mastitis infection, lipid metabolism, immune response

\footnotetext{
*Correspondence: geninis@vet.upenn.edu

† Contributed equally

${ }^{1}$ Parco Tecnologico Padano - CERSA, Via Einstein, 26900 Lodi, Italy

Full list of author information is available at the end of the article
} 


\section{Background}

In the last decade, gene expression profiling microarrays have been widely used in animal genomics and this technique has enabled researchers to monitor, on a broad scale, the effects of pathogens on host cells and tissues, aiming to gain insight into the molecular mechanisms that are involved in the host-pathogen interactions. Mastitis is one of the most costly diseases of the dairy industry, which makes it among the major concerns for the livestock sector [1]. As a consequence, numerous gene expression studies on mastitis in different host species infected with various pathogens are publicly available. However, due to the high costs of this approach, most individual studies have been carried out on limited numbers of technical and biological replicates. Furthermore, different and improved microarray platforms have been used over time, due to the increased availability of improved microarray tools tailored to the genome sequence of most livestock species.

Meta-analysis can be used to combine or integrate the data or results of independent studies. It allows a more objective appraisal of evidence than individual studies and has been widely used to interpret contradictory results from various studies or overcome the problem of reduced statistical power in studies with small sample sizes (reviewed by $[2,3]$ ). The applicability of meta-analysis to microarrays was initially demonstrated by $[4,5]$. Subsequently, several different meta-analysis applications have been developed in order enable the integration of independent microarray expression studies, e.g. through the combination of effect sizes [6], the comparison of data intersections (comparative meta-profiling) $[7,8]$, the integration of data from Affymetrix arrays through reannotation and common pre-processing methods [9], the quantification of similarities in the literature (with an algorithm called LAMA, Literature-Aided Meta-Analysis) [10], the development of a ranking aggregation approach [11], and the application of improved and meta-analysis adapted normalization methods [12-14]. Meta-analysis methods have also been applied to characterize the properties of promoters to regulate transcription of up-regulated genes [15].

As p-values are usually available for each gene in each study, the main focus of the current meta-analysis approach was to increase the reliability of statistical evidence, by combining p-values across several, often heterogeneous, experiments. Various statistics have been suggested to combine p-values [2,4,16-19]. In particular, the meta-analysis tool chosen for this study, Pointillist $[20,21]$, uses and extends the Fisher inverse chi-square method for p-value combination (reviewed by [22]) by calculating different weights (i.e. reliability/representativeness parameters which represent relative measures of statistical power of all datasets analysed) that are used to transform the p-values of each experiment. By doing so, Pointillist takes into consideration the various experimental design differences and the high heterogeneity of the datasets, including the use of different platforms, that has been a major hindrance to meta-analysis so far.

The large quantity of microarray data available for mastitis in ruminants provides an attractive opportunity for a meta-analysis approach. Gene expression commonalities shared across pathogens and host species may contribute to understanding the disease and its physiology, as well as pinpoint the most promising direction of research to identify effective biomarkers. Indeed, several innate immune responses, especially to pathogen-associated molecular patterns, show evolutionary conservation, thus increasing the feasibility of meta-analysis of gene expression data across species [23]. In controlled in vitro cultures of macrophages [24] and dendritic cells [25], a similar shared induction of common gene expression patterns in responses to a broad range of bacteria has been observed. Furthermore, previous meta-analysis results [26] showed common clusters of affected genes across larger numbers of pathogens and studies.

The aim of this project was to identify common sets of differentially expressed genes regulated by three mastitis pathogens (S. aureus, S. uberis, and E. coli) in three affected ruminant species (cattle, goat, and sheep). Economy-wise, these three species are by far the most important for the dairy industry. For this purpose we used the program Pointillist $[20,21]$ and, by combining similar time points of different experiments, we created four main lists of genes differentially modulated by mastitis infection. In vitro experiments were treated in the same way as in vivo experiments as the weighting mechanism of Pointillist provided protection against potential response-dependant biases.

We then used the Ingenuity Pathways Analysis (IPA; http://www.ingenuity.com) software to retrieve the canonical pathways, biological functions and networks that were most significantly associated with the lists of affected genes. IPA is a curated database and web-based analysis system that delivers an assessment of signaling and metabolic pathways, molecular networks, as well as key biological and disease processes that are most significantly perturbed in a gene set of interest. For each metaanalysis combination tested with IPA, the five most affected canonical pathways and the five most affected biological functions belonging to the sub-group "molecular and cellular functions" are discussed in detail.

All the meta-analysis combinations highlighted a predominance of gene pathways and biological functions related to immune response and to lipid metabolism. The results show common but also combination-specific affected genes and pathways and provide new avenues for future studies. 


\section{Results and discussion}

Combination of time points of mastitis experiments with Pointillist

Different combinations of time points from individual experiments (Table 1) were selected to represent four main categories of response to mastitis infection. These combinations were performed with Pointillist and were named: (I) overall response, (II) early stage response, (III) late stage response, and (IV) cattle-specific response (Table 2). No goat- or sheep-specific responses were studied because of the more limited number of experiments and time points for those species.

The combination (I) overall response included each animal species (cattle, sheep, goat) and all the time points (see Tables 1 and 2) in order to capture the heterogeneity of all datasets. In order to avoid bias towards cattle, for which more datasets were available, the list of combined p-values, or so-called "Combined Effective Significances", for each probe was obtained by a stepwise process. First, species-specific p-value lists were obtained. A single Pointillist run was applied to obtain the goat-specific (combination of time points $\{12\}+\{13\}$ $+\{16\})$ and the sheep-specific (combination of time points $\{14\}+\{15\})$ p-value lists. To obtain the cattle-specific p-value list, (IV) cattle-specific response, two Pointillist processing steps were required. Firstly, the time points for each separate bovine microarray experiment, e.g. 1A (combination of time points $\{1\}+\{2\}+\{3\}), 1 B$ (combination of time points $\{4\}+\{5\}+\{6\}), 1 C$ (combination of time points $\{7\}+\{8\}$ ), 2 (time point $\{9\}$ ), and 3 (combination of time points $\{10\}+\{11\}$ ) were analyzed separately with an initial Pointillist run. Subsequently, the resulting p-values of each experiment were combined with a second Pointillist run. The final combined p-values for (I) overall response were obtained by combining with an additional Pointillist run the three species-specific p-value lists.

The combined p-value lists for (II) early stage and (III) late stage responses were obtained by combining the time points for which respectively "no signs" or "clear signs" of mastitis were observed. In particular, inclusion of in vivo time points $\{1\}+\{6\}+\{7\}+\{12\}$ in list (II) and $\{3\}$ $+\{8\}+\{13\}$ in list (III) (Table 2), was supported by the absence or the clear presence, respectively, of clinical signs of acute mastitis such as increased SCC count, decreased milk yield, leukopenia, fever, and udder swelling (Table 1). The absence of clinical signs in time points $\{1\},\{6\}$, and $\{7\}$ had been confirmed by real-time PCR of indicators for acute mastitis (TLR2, TLR4, and $\beta$-defensins; [27]). The early time points $\{10\}$ and $\{14\}$ of the in vitro studies were assigned to the early stage response because minimal or no reaction or cell death was observed, while the later time points $\{11\}$ and $\{15\}$ were included in the late stage response because clear reaction or physiological deformation and death of the cells were observed. Time point $\{9\}$ was neither included in the early stage nor in the late stage response because it was the only available time point for the pathogen $S$. uberis.

\section{Overall response to mastitis infection}

Because we pooled microarrays of different designs, only 13,162 probes could be analyzed in combination (I) overall response. Of the 498 probes identified by Pointillist as being significantly altered ( $\mathrm{p} \leq 0.05$ ), a total of 298 unique genes were present in the IPA knowledge database [Additional file 1]. The relative weights assigned by Pointillist to each species-specific experiment were 0.82 for cattle (experiments 1,2 , and 3), 0.08 for goat (experiments 4 and 6), and 0.09 for sheep (experiment 5). This indicates that the cattle data had greater statistical power than the goat- and sheep-specific data, which were similar in terms of statistical power.

\section{Affected canonical pathways}

The 5 canonical pathways identified by IPA as being most significantly associated to this list of 298 genes were protein ubiquitination, acute phase response signaling, lipid antigen presentation by $C D 1$, oncostatin $M$ signaling, and antigen presentation pathway [Additional file 2].

The protein ubiquitination pathway has a fundamental role in a myriad of cellular processes, including cell proliferation, antigen presentation, and regulation of both innate and adaptive immune responses [28,29]). This pathway was present within the 5 most significant canonical pathways of the other 3 main gene lists [Additional file 2], confirming its role in defence against pathogens, including bacteria [30]. The acute phase response is a rapid, non-specific inflammatory response that provides protection against microorganisms, and is associated with the expression of several cytokines [31]. Furthermore, bovine acute phase response has been shown to be activated by lipopolysaccharide (LPS) [32] and by E. coli [33], possibly through its LPS. The lipid antigen presentation by CD1 and the antigen presentation pathways are important to the development of innate and adaptive immunity [34]. Finally, oncostatin $M$ signaling is known to be responsible for the initiation and progression of inflammation and the acute phase response [35]. These findings suggest that the alteration of immune response and lipid metabolism are hallmarks of the response to infections causing mastitis.

\section{Affected biological functions}

[Additional file 3] reports the complete lists of affected biological functions for all the sub-groups "Diseases and disorders", "Physiological system development and 
Table 1 Summary of the microarray datasets on mastitis infection included in meta-analysis

\begin{tabular}{|c|c|c|c|c|c|c|c|}
\hline $\begin{array}{l}\text { Experiment } \\
\# \\
\text { (Institution) }\end{array}$ & $\begin{array}{l}\text { Host } \\
\text { species } \\
\text { (\# of } \\
\text { biological } \\
\text { replicates) }\end{array}$ & Pathogen & Challenge system & $\begin{array}{l}\text { Bovine CDNA } \\
\text { microarray }\end{array}$ & $\begin{array}{c}\text { Time } \\
\text { after } \\
\text { infection } \\
\text { \{time } \\
\text { point }\end{array}$ & Signs of infection & References \\
\hline \multirow[t]{3}{*}{$\begin{array}{l}\text { 1A (RI/ } \\
\text { RIBFA) }\end{array}$} & Cattle (4) & E. coli & $\begin{array}{l}\text { Intramammary challenge. } \\
\text { Sampled material: lobulo- } \\
\text { alveolar mammary tissue } \\
\text { (in vivo) }\end{array}$ & $\begin{array}{l}\text { ARK-genomics } \\
20 \mathrm{k}\end{array}$ & $6 \mathrm{~h}\{1\}$ & $\begin{array}{l}\text { No clinical signs and no alteration of } \\
T L R 2, T L R 4 \text {, } \\
\text { and } \beta \text {-defensins expressions. }\end{array}$ & {$[27,63,64]$} \\
\hline & & & & & $12 \mathrm{~h}\{2\}$ & $\begin{array}{l}\text { Mild clinical signs and small changes of } \\
\text { TLR2, TLR4, and } \beta \text {-defensins expressions. }\end{array}$ & \\
\hline & & & & & $24 \mathrm{~h}\{3\}$ & $\begin{array}{l}\text { Acute clinical signs (including increased } \\
\text { SCC count, decreased milk yield, } \\
\text { leukopenia, fever, udder swelling) and } \\
\text { up-regulation of TLR2, TLR4, and } \beta \text { - } \\
\text { defensins expressions }\end{array}$ & \\
\hline \multirow[t]{3}{*}{$\begin{array}{l}\text { 1B (RI/ } \\
\text { RIBFA) }\end{array}$} & Cattle (4) & S. aureus & $\begin{array}{l}\text { Intramammary challenge. } \\
\text { Sampled material: lobulo- } \\
\text { alveolar mammary tissue } \\
\text { (in vivo) }\end{array}$ & $\begin{array}{l}\text { ARK-genomics } \\
20 \mathrm{k}\end{array}$ & $6 \mathrm{~h}\{4\}$ & $\begin{array}{l}\text { No clinical signs and no alteration of } \\
T L R 2, T L R 4 \text {, and } \beta \text {-defensins expressions. }\end{array}$ & {$[27,63,64]$} \\
\hline & & & & & $12 \mathrm{~h}\{5\}$ & $\begin{array}{l}\text { No clinical signs and no alteration of } \\
\text { TLR2, TLR4, and } \beta \text {-defensins expressions. }\end{array}$ & \\
\hline & & & & & $24 \mathrm{~h}\{6\}$ & $\begin{array}{l}\text { No clinical signs and no alteration of } \\
T L R 2, T L R 4 \text {, and } \beta \text {-defensins expressions. }\end{array}$ & \\
\hline \multirow[t]{2}{*}{$\begin{array}{l}1 \mathrm{C}(\mathrm{RI} / \\
\mathrm{RIBFA})\end{array}$} & Cattle (4) & S. aureus & $\begin{array}{l}\text { Intramammary challenge. } \\
\text { Sampled material: lobulo- } \\
\text { alveolar mammary tissue } \\
\text { (in vivo) }\end{array}$ & $\begin{array}{l}\text { ARK-genomics } \\
20 \mathrm{k}\end{array}$ & $12 \mathrm{~h}\{7\}$ & $\begin{array}{l}\text { No clinical signs and no alteration of } \\
\text { TLR2, TLR4, and } \beta \text {-defensins expressions. }\end{array}$ & {$[27,63,64]$} \\
\hline & & & & & $72 \mathrm{~h}\{8\}$ & $\begin{array}{l}\text { Acute clinical signs (including increased } \\
\text { SCC count, decreased milk yield, } \\
\text { leukopenia, fever, udder swelling) and } \\
\text { up-regulation of } T L R 2, T L R 4 \text {, and } \beta \text { - } \\
\text { defensins expressions }\end{array}$ & \\
\hline $2(\mathrm{CVI}-\mathrm{L})$ & Cattle (3) & S. uberis & $\begin{array}{l}\text { Udder samples containing } \\
\text { all layers including } \\
\text { epithelia, muscle tissue } \\
\text { and mammary gland } \\
\text { tissue. In affected samples } \\
\text { neutrophils were also } \\
\text { present (in vivo) }\end{array}$ & $\begin{array}{l}\text { ARK-genomics } \\
20 \mathrm{k}\end{array}$ & $\begin{array}{c}36 \mathrm{~h}-72 \mathrm{~h} \\
\{9\}\end{array}$ & $\begin{array}{l}\text { Culling when clear clinical signs were } \\
\text { seen. Sample selection from various } \\
\text { locations of control and infected } \\
\text { mammary gland quarters based on clear } \\
\text { microscopic and macroscopic } \\
\text { observations }\end{array}$ & - \\
\hline \multirow[t]{2}{*}{3 (NSVS) } & Cattle (6) & S. aureus & $\begin{array}{l}\text { Blood derived primary } \\
\text { macrophage cells (in vitro) }\end{array}$ & $\begin{array}{l}\text { ARK-genomics } \\
17 \mathrm{k}\end{array}$ & $2 \mathrm{~h}\{10\}$ & Few genes responding, no cell death. & - \\
\hline & & & & & $6 \mathrm{~h}\{11\}$ & $\begin{array}{l}\text { Many genes responding, beginning } \\
\text { signs of cell deformation and death }\end{array}$ & \\
\hline \multirow[t]{2}{*}{$\begin{array}{l}\mathbf{4} \text { (UNIMI/ } \\
\text { PTP/CNR) }\end{array}$} & Goat (3) & S. aureus & Leukocytes in milk (in vivo) & NBFGC & $12 \mathrm{~h}\{12\}$ & $\begin{array}{l}\text { No clinical signs and no alteration of } \\
\text { milk. }\end{array}$ & {$[65,66]$} \\
\hline & & & & & $24 \mathrm{~h}\{13\}$ & $\begin{array}{l}\text { Clear clinical signs (increased SCC count, } \\
\text { decreased milk yield, fever) }\end{array}$ & \\
\hline \multirow[t]{2}{*}{5 (INRA) } & Sheep (8) & S. aureus & $\begin{array}{l}\text { Bone marrow derived } \\
\text { primary dendritic cells (in } \\
\text { vitro) }\end{array}$ & $\begin{array}{l}\text { ARK-genomics } \\
17 \mathrm{k}\end{array}$ & $3 \mathrm{~h}\{14\}$ & No cell death. & - \\
\hline & & & & & $8 \mathrm{~h}\{15\}$ & $\begin{array}{l}\text { Clear deformation and death of } \\
\text { dendritic cells }\end{array}$ & \\
\hline $\begin{array}{l}6 \text { (UNIMI/ } \\
\text { PTP/CNR) }\end{array}$ & Goat (10) & S. aureus & Leukocytes in milk (in vivo) & Combi-Matrix & $24 \mathrm{~h}\{16\}$ & $\begin{array}{l}\text { Clinical signs (increased SCC count, } \\
\text { decreased milk yield, fever, udder } \\
\text { swelling) }\end{array}$ & - \\
\hline
\end{tabular}

The experimental numbers are reported with the names of the institution where they were conducted, host species and number of replicates, pathogens, challenge systems, microarrays names, time period of observations after infection \{in parenthesis the time point \#, see also Table 2\}, signs of infection, and corresponding references.

Note: ARK-genomics: centre for comparative \& functional genomics, Scotland; CNR: Institute of Agricultural Biology and Biotechnology, National Research Council, Italy; CVI-L: Central Veterinary Institute of Wageningen UR, Lelystad, NL; INRA: Institute National de la Recherche Agronomique, France; NBFGC: National Bovine Functional Genomics Consortium, USA; NSVS: Norwegian School of Veterinary Science, Norway; PTP: Parco Tecnologico Padano (PTP), Italy; RI: Roslin Institute and R(D)SVS, University of Edinburgh (UEDIN), UK; RIBFA: Research Institute for the Biology of Farm Animals, Germany; UNIMI: Università degli Studi di Milano, Department of Veterinary Pathology, Hygiene and Public Health, Italy. Microarrays are described in the Materials and Methods section of text. 
Table 2 Combination of experiments and time points to create the 4 main responses to mastitis infection

\begin{tabular}{|c|c|c|c|c|c|c|c|c|}
\hline \multirow[b]{2}{*}{ Experiment \# } & \multicolumn{8}{|c|}{ Time after infection } \\
\hline & $2 \mathrm{~h}$ & $3 \mathrm{~h}$ & $6 \mathrm{~h}$ & $8 \mathrm{~h}$ & $12 \mathrm{~h}$ & $24 \mathrm{~h}$ & $36 \mathrm{~h}-72 \mathrm{~h}$ & $72 \mathrm{~h}$ \\
\hline 1A: E. coli in cattle (in vivo) & & & $\begin{array}{c}\{1\} \\
\mathrm{I}, \mathrm{II}, \mathrm{IV}\end{array}$ & & $\begin{array}{l}\{2\} \\
\text { I, IV }\end{array}$ & $\begin{array}{c}\{3\} \\
\text { I, III, IV }\end{array}$ & & \\
\hline 1B: S. aureus in cattle (in vivo) & & & $\begin{array}{l}\{4\} \\
I, I V\end{array}$ & & $\begin{array}{l}\{5\} \\
I, I V\end{array}$ & $\begin{array}{l}\{6\} \\
\mathrm{I}, \mathrm{II}, \mathrm{IV}\end{array}$ & & \\
\hline 1C: S. aureus in cattle (in vivo) & & & & & $\begin{array}{c}\{7\} \\
\mathrm{I}, \mathrm{II}, \mathrm{IV}\end{array}$ & & & $\begin{array}{c}\{8\} \\
\text { I, III, IV }\end{array}$ \\
\hline 2: S. uberis in cattle (in vivo) & & & & & & & $\begin{array}{l}\{9\} \\
I, I V\end{array}$ & \\
\hline 3: S. aureus in cattle macrophages (in vitro) & $\begin{array}{c}\{10\} \\
I, I I, I V\end{array}$ & & $\begin{array}{c}\{11\} \\
\text { I, III, IV }\end{array}$ & & & & & \\
\hline 4: S. aureus in goat (in vivo) & & & & & $\begin{array}{l}\{12\} \\
\mid, \|\end{array}$ & $\begin{array}{l}\{13\} \\
|,| I \mid\end{array}$ & & \\
\hline 5: S. aureus in sheep dendritic cells (in vitro) & & $\begin{array}{l}\{14\} \\
\text { I, II }\end{array}$ & & $\begin{array}{l}\{15\} \\
|,| I \mid\end{array}$ & & & & \\
\hline 6: S. aureus in goat (in vivo) & & & & & & $\begin{array}{c}\{16\} \\
\mid\end{array}$ & & \\
\hline
\end{tabular}

Combination of microarray data from a total of 6 different experiments and 16 different time points (\{in parentheses\}, see also Table 1 and text for details) to analyse 4 different responses to mastitis infection: (I) overall response, (II) early stage response, (III) late stage response, and (IV) cattle-specific response.

function" and "Molecular and cellular functions". The five most significant molecular and cellular functions altered during the overall response to mastitis were cell death, cellular movement, cellular growth and proliferation, cell-to-cell signaling and interaction, and lipid metabolism. The first three altered functions were among the 5 most affected in all 4 main responses [in bold in Additional file 3].

Perturbation of the lipid metabolism might affect the lipid antigen presentation by CD1 pathway [Additional file 2], which consists of a conserved family of MHClike glycoproteins specialized in capturing lipid and glycolipid antigens for presentation to T lymphocytes [36]. A relevant correlation between lipid metabolism and mastitis infection caused by $S$. uberis in mammary tissues has indeed been reported [37]. Furthermore, lipid metabolism has been identified as one of the most altered biological functions in cows fed at different energy balance diets [38] and it has been associated with differentially regulated proteins detected in cows infected with E. coli and S. aureus [39]. Consequently, IPA was used to further dissect the main sub-functions linked to lipid metabolism. Metabolism of long chain fatty acids, accumulation of oleic acids, internalization of lipids, and uptake of fatty acids and arachidonic acid were the top 5 annotated functions related to lipid metabolism and altered during the overall response to mastitis [Additional file 4]. The affected biological functions further confirm a relevant role of the lipid metabolism during response to infections causing mastitis.

Early stage and late stage responses to mastitis infection Of the 20,527 probes analyzed by Pointillist for the early and late stage responses, 1,129 and 1,046, respectively, were significantly altered $(\mathrm{p} \leq 0.05)$. Of these, a total of 639 and 631 unique genes, respectively, were present in the IPA knowledge database [Additional file 1].

\section{Affected canonical pathways}

In addition to the protein ubiquitination and polyamine regulation pathways that were common for both combinations, the early stage response was characterized by pathways closely related to metabolic regulation, including hypoxia signaling, pyruvate metabolism, and endoplasmic reticulum (ER) stress [Additional file 2]. Hypoxia inducible factors are known to control innate immunity and gene expression of pro-inflammatory molecules [40], and correlations between ER stress, immune response and apoptosis have been reported [41]. Also, pyruvate accumulation caused by inhibition of lipid metabolism has indeed been shown to prompt hypoxia signaling in mastitis in cattle [37]. The significant alterations of these closely linked pathways suggests that stress signals are launched by the host cells as part of the activation of the immune response early during infection, i.e. prior to observation of clear phenotypes related to mastitis.

On the other hand, the late stage response was specifically represented by pathways directly involved in the immune response, i.e. IL- 6 signaling, LXR/RXR activation and IL-10 signaling [Additional file 2]. A close relationship between polyamine regulation, in particular the sub-group spermine, and IL-10 signaling has been reported in macrophages [42]. Other studies reported an increase of IL- 6 and IL-10 expression during mastitis infection [43,44]. As persistence or over-prolongation of inflammation is harmful for cells [45], the activation of the IL-10 signaling might be a beneficial mechanism 
adopted by the cells during this stage of mastitis infection to limit and terminate the inflammatory response.

\section{Affected biological functions}

Cellular growth and proliferation, cell death and cellular movement were 3 of the top 5 significant molecular and cellular functions identified by IPA for both time-dependant responses [Additional file 3]. Two protein-related functions (post-translational modification and protein folding) were specific for the early stage response, while cellular functions (cellular assembly and organization, cell-to-cell signaling and interaction) were specific for the late stage response [Additional file 3].

Lipid metabolism was significantly altered during both early $(p=3.5 \mathrm{E}-04)$ and late stage $(\mathrm{p}=3.1 \mathrm{E}-06)$ infections, although it was not among the five most significant. The altered LXR/RXR signaling pathway [Additional file 2] is known to be implicated in the regulation of the lipid metabolism [46]. Since lipid metabolism was among the top 5 affected molecular and cellular functions in the overall analysis (gene list I), the main altered sub-functions of the lipid metabolism were identified by IPA. Hydrolysis of phosphatidylinositol phosphate, phosphatidylinositol 4,5-diphosphate, and phosphtidylinositol 5-phosphate, as well as metabolism of fatty acid and lipids were the most significant affected sub-functions for the early stage response [Additional file 4]. For the late stage response on the other hand, quantity of fatty acid, oleic acid, and lipid, as well as synthesis of lipid and cholesterol were the identified top affected sub-functions. These results seem to suggest that whilst during the early stage response there might be a "general" deregulation of the lipid metabolism, during the late stage response the cells might react to the infection by synthesizing, taking up, or incorporating lipids and fatty acids.

\section{Relevance of the XBP1 gene during the early stage of infection}

The lists of affected genes during the early and late stage responses were analyzed with the IPA feature "pathway building", which shows the main relationships and connections among affected genes belonging to altered canonical pathways. The two genes X-box binding protein 1 (XBP1) and sterol regulatory element binding transcription factor 1 (SREBF1) are of particular relevance in early and late stage infection, respectively. Both belong to canonical pathways that were among the 5 most affected (XBP1 to ER stress and SREBF1 to LXR/RXR activation) [Additional file 2] and, in agreement with their function as transcription factors, they were directly linked to the highest number of other affected genes [Additional file 5: Supplemental Figures $\mathrm{S} 1 \mathrm{~B}$ and S2].
$X B P 1$ and the additional transcription factors $A T F 4$, as well as the molecular chaperone $D N A J B 3$ and the heatshock protein gene HSPA5, which are key molecules of ER stress, one of the 5 most significantly affected pathways [Additional file 2], were altered during the early stage response. Comparable results have been reported in other studies in dairy cows where expressions of ATF4, XBP1, and $D N A J B 3$ were altered in ER stress generated by a negative energy balance [47]. Hence, XBP1 might have a central role in launching stress signals in preparation for an adequate immune response during the early stage of mastitis infection, as it is also involved in cytokine production in different cell types, including macrophages [48,49]. This gene directly regulates the expression of the affected genes COPZ1, DDOST, KDELR2, KDELR3, RPN1, $S E C 23 B, S E C 24 D, S E C 61 A 1, S R P R$, as well as genes of the proteasome and the MHC Class II complex [Additional file 5: Supplemental Figure S1B]. Indirectly, $X B P 1$ is also linked to many more affected genes [Additional file 5: Supplemental Figure S1A]. In line with our results, alteration of several genes that directly interact with $X B P 1$ (e.g. COPZ1, DDOST, KDELR3, RPN1, SEC23B, SEC24D, $S E C 61 A 1$, and $S R P R$ ) have also been reported in fibroblasts over-expressing XBP1 [50].

\section{Relevance of the SREBF1 gene during the late stage of infection}

In the late stage response, $S R E B F 1$ directly interacts with several affected lipogenic genes, i.e. TRAF3IP3, CD36, SCD, SOD1, IDH1, THRB, RETN, PMVK, DBI, UCP2, HBS1, SC4MOL, and CYP27A1 [Additional file 5: Supplemental Figure S2]. Among these, expressions of TRAF3IP3, CD36, and SCD were also reported to be altered during infection of cattle mammary tissues with S. uberis [37]. SREBF1 is a component of the LXR/RXR pathway, one of the 5 most affected pathways, confirming the relationship between LXR/RXR signalling and lipid metabolism. This relationship might explain the observed depression of milk fat synthesis during mastitis infection in ruminants.

\section{Early and late stage specific responses}

In order to better understand the differences between the two different time-related responses, the (II) early stage and the (III) late stage responses were subjected to IPA analysis taking into account only the subset of affected genes differentiating the two lists. While 375 genes belonged to list (II) and not list (III) (list V early specific response), 367 genes belonged to list (III) and not list (II) (list VI late specific response) [Additional file 1].

\section{Affected canonical pathways}

The results of the canonical pathway analysis confirmed that during early specific response there is 
intensification of cell metabolism (exemplified by the pyruvate and butanoate metabolism), the protein ubiquitination pathway, as well as the stress signal pathways, e. g. hypoxia in the cardiovascular system and Ataxia Telangiectasia Mutated (ATM) signaling [Additional file 2]. During the late specific, the top affected pathways (IL-6 signaling, polyamine regulation, acute phase response signaling, "role of macrophages, fibroblasts and endothelial cells in rheumatoid arthritis", and Fc receptormediated phagocytosis in macrophages and monocytes) indicated an intense activity of the immune response, with the possible involvement of macrophages.

\section{Affected biological functions}

None of the top 5 molecular and cellular functions were in common between the two time-specific gene lists (V) and (VI) [Additional file 3]. Similarly to the previous analysis of gene list (II) early stage response and (III) late stage response, the early specific response genes showed molecular and cellular functions related to metabolism (carbohydrate and lipid), biochemistry and protein synthesis (post translational modification and folding), while the late specific response were mainly involved in cellular functions (movement, growth and proliferation, assembly and organization, function and maintenance), as well as cell morphology.

\section{Cattle-specific response to mastitis infection}

Pointillist identified 669 out of 19,448 common probes that were significantly altered $(p \leq 0.05)$ in the cattlespecific response to mastitis. The weights given by Pointillist to experiments $1 \mathrm{~A}, 1 \mathrm{~B}, 1 \mathrm{C}, 2$, and 3 were 0.27 , $0.23,0.28,0.17$, and 0.04 , respectively, showing that the in vitro data set had a lower statistical power than the other data sets. Of the 669 probes, a total of 421 unique genes were present in the IPA knowledge database.

\section{Affected canonical pathways}

Besides polyamine regulation and protein ubiquitination, the top canonical pathways characterizing the cattle-specific response were acute phase response, lipid antigen presentation by CD1 (also identified in the overall response), two highly relevant pathways for immune response, and the inositol metabolism [Additional file 2], which is involved in T-cell, B-cell, and neutrophil development and function [51]. These results indicate a link between mastitis and immune response involving $\mathrm{T}$ and $\mathrm{B}$ cells.

\section{Affected biological functions}

In accordance with the top canonical pathway analysis, the altered molecular and cellular functions identified by IPA (i.e. antigen presentation, cell death, cell to cell interaction, and cellular growth, proliferation and movement) reflected an intensification of the immune response during cattle-specific response to mastitis infection [Additional file 3].

Alteration of the expression of genes involved in immune response, antigen presentation, apoptosis, and acute phase response have been also reported in a similar study [52].

Lipid metabolism was also significantly affected ( $\mathrm{p}=$ 4.9E-05), although it was not included among the five most significant. Sub-functions of lipid metabolism that were altered during the cattle-specific response included uptake of arachidonic acid, metabolism of long chain fatty acid, internalization of cholesterol, transport and quantity of fatty acid [Additional file 4]. These findings further underline that lipid metabolism is tightly linked to immune response and that lipid antigen presentation might represent an interesting candidate pathway for future work to gain new insights into the host-pathogen interplay in mastitis.

\section{Comparison of the host expression profiles in the different experiments and time points}

Next, we compared the different cattle microarray datasets, focusing on the impact of the use of different infective agents (three of the major mastitis-causing pathogens: E. coli, S. aureus, and S. uberis) and the patterns of gene response that they caused in the host.

When clustering the expression profiles of the cattlespecific response time points (see heat map in Figure 1) the first clustering step is primarily based on experiment number (Tables 1 and 2) (experiment 1A time points $\{1-3\}$ clustered together, experiment $1 \mathrm{~B}$ time points $\{4-$ 5 ) clustered together, experiment $1 \mathrm{C}$ time points $\{7-8\}$ clustered together along with experiment $1 \mathrm{~B}$ time point $\{6\}$, and experiment 3 time points $\{10-11\}$ clustered together). It is not unexpected that expression profiles of different time points of the same microarray experiment cluster together. The final clustering steps indicated a pathogen-specific pattern as all $S$. aureus time points (along with the $S$. uberis time point $\{9\}$ ) clustered together, separately from the $E$. coli time points. No inter-laboratory or inter-array clustering was observed. For instance, the E. coli data (experiment 1A) did not cluster with the data from the other experiments (1B and $1 \mathrm{C}$ ) performed in the same institution (Figure 1 ). This provides reassurance that the data were not significantly biased towards the experimental conditions used.

\section{Comparison of the strength of the host response to the 3 different pathogens}

We also compared the magnitude of fold change differences in gene expression in the cattle host caused by $E$. coli, S. aureus, or S. uberis infections with the MaSigPro package [53]. Figure 2 shows that, in general, the E. coli infection caused a stronger response in the host than 


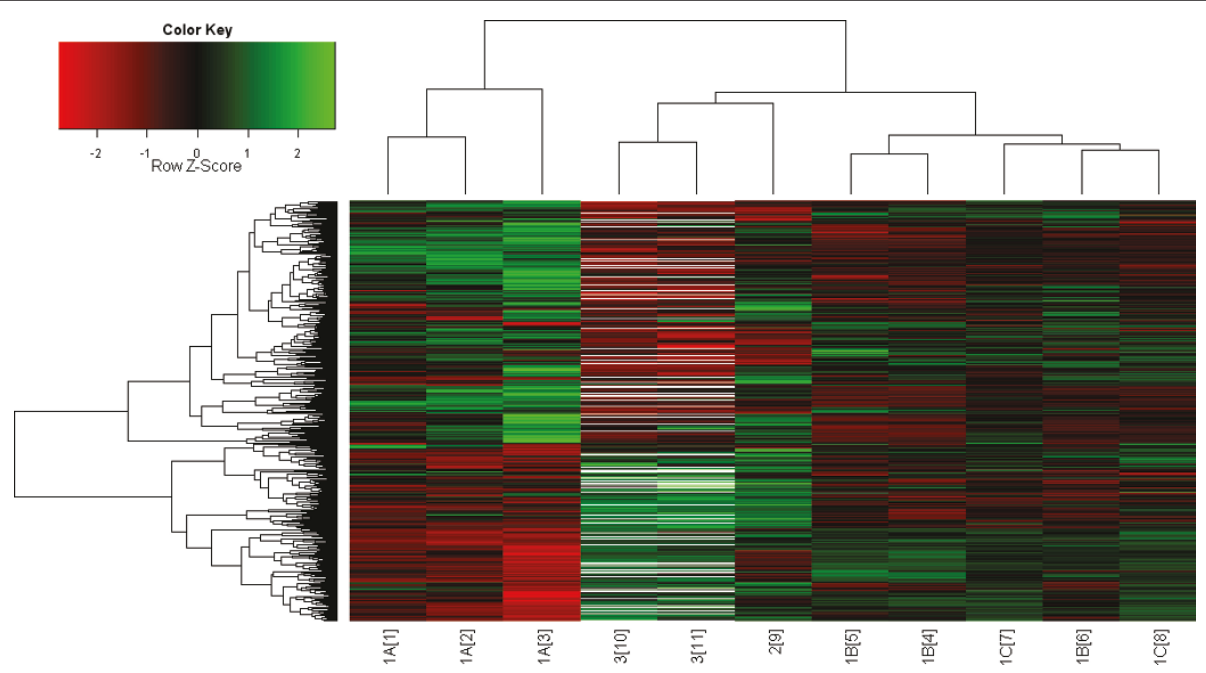

Figure 1 Heat map showing cluster analysis of the microarray experiments used in the cattle-specific response to three different pathogens (E. coli, S. aureus, and S. uberis). The X-axis shows the time points ffrom 1 to 11$\}$ of each different cattle experiment (1A, 1B, 1C, 2, and 3; Table 2), while the $y$-axis displays the clustered genes. The map itself contains gene fold changes Z-score normalized over all time points. They are color coded, with red corresponding to down-regulation and green to up-regulation. White lines in experiment 3 represent missing genes not present on the microarray. The first clustering step is primarily based on experiment number (Tables 1 and 2) (experiment $1 \mathrm{~A}\{1-3\}$ clustered together, 1B $\{4-5\}$ clustered together, $1 \mathrm{C}\{7-8\}$ clustered together along with the $1 \mathrm{~B}$ time point $\{6\}$, and $3\{10-11\}$ clustered together). The final clustering steps indicated a pathogen-specific pattern as all S. aureus time points (along with the S. uberis time point $\{9\}$ ) clustered together, separately from the E. coli time points.

the S. aureus and S. uberis infections. High fold change differences were induced by $E$. coli, especially at $24 \mathrm{~h}$ post infection (experiment $1 \mathrm{~A}$, time point $\{3\}$ ), and to a lesser extent by $S$. uberis between 36 and $72 \mathrm{~h}$ post infection (experiment 2, time point $\{9\}$ ).

Although this finding might be related to the specific experimental conditions used in the different experiments, it reflects previous observations that $E$. coli infection is very acute at $24 \mathrm{~h}$, but not yet at $6 \mathrm{~h}$ PI [52], and that it is very acute compared to other pathogens
$[39,54]$. Furthermore, the results suggest that $S$. aureus, but not E. coli, frequently causes subclinical, chronic infections of the mammary gland and hence elicits an inadequate mammary immune response $[27,55]$.

\section{Comparison between meta-analysis of (IV) cattle-specific response and individual experiments}

To better quantify the additional power of the proposed meta-analysis approach, we compared the list of 421 affected genes identified with the meta-analysis of (IV)

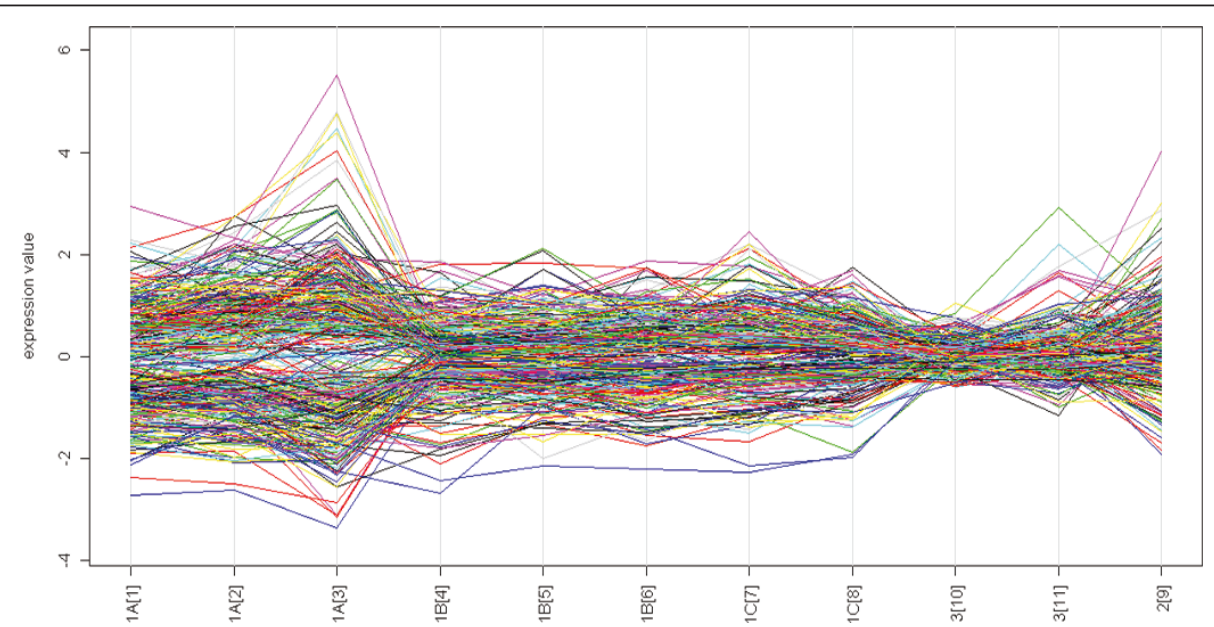

Figure 2 Magnitude of fold change expression characterizing E. coli, S. aureus, and S. uberis infections in cattle. The x-axis shows the time points \{from 1 to 11$\}$ of each different cattle experiment (1A, 1B, 1C, 2, and 3; Table 2), while the y-axis shows the fold changes for each gene (each line). High differences are observed especially during infection with $E$. coli $(1 \mathrm{~A}\{3\})$, and to a lesser extent with $S$. uberis $(2\{9\})$. 
cattle-specific response with the lists of affected genes (using the Benjamini-Hochberg FDR-correction [56], p $\leq 0.05$ ) in individual experiments (i.e. experiment $1 \mathrm{~A}$ time point $\{3\}$ and experiment 2 time point $\{9\}$ ). The results showed that 25 affected genes were in common between the three lists, while 268, 581, and 15 genes were specific for (IV) cattle-specific response, experiment $1 \mathrm{~A}$ time point $\{3\}$, and experiment 2 time point $\{9\}$, respectively [Additional file 5: Supplemental Figure S3 and the corresponding gene lists in Additional file 6].

Next, applying IPA on the lists of affected genes, we identified the 5 most affected canonical pathways and molecular and cellular functions of the individual experiments. The canonical pathways protein ubiquitination $(\mathrm{p}=2.9 \mathrm{E}-09)$, ephrin receptor signaling $(\mathrm{p}=$ $1.1 \mathrm{E}-06)$, regulation of actin-based motility by Rho ( $\mathrm{p}=$ 5.7E-06), actin cytoskeleton signaling ( $p=3.6 \mathrm{E}-05)$, and germ cell-Sertoli cell junction signaling ( $\mathrm{p}=5.5 \mathrm{E}-05)$, as well as the molecular and cellular functions cell death, cellular growth and proliferation, cell signaling, cellular movement, and lipid metabolism were the most affected within the 745 affected genes of experiment $1 \mathrm{~A}$ time point $\{3\}$. Canonical pathways and molecular and cellular functions in common with the five most affected identified by meta-analysis of the (IV) cattle-specific response [Additional files 2 and 3] included polyamine regulation, as well as cell death, cellular growth and proliferation, and cellular movement, respectively.

The IPA canonical pathways iCOS-iCOSL signaling in $\mathrm{T}$ Helper cells $(\mathrm{p}=4.7 \mathrm{E}-04)$, activation of IRF by cytosolic pattern recognition receptors $(\mathrm{p}=1.1 \mathrm{E}-03)$, dendritic cell maturation ( $p=1.8 \mathrm{E}-03)$, production of nitric oxide and reactive oxygen species in macrophages $(\mathrm{p}=$ $1.8 \mathrm{E}-03)$, and communication between innate and adaptive immune cells ( $\mathrm{p}=3.0 \mathrm{E}-03)$, as well as the molecular and cellular functions cellular growth and proliferation, cell death, cell-to-cell signaling and interaction, cellular function and maintenance, and gene expression were the most affected within the 55 genes of experiment 2 time point $\{9\}$. None of the canonical pathways were in common with the most affected of the meta-analysis of the (IV) cattle-specific response; whereas cell death, cellular growth and proliferation, and cell-to-cell signaling and interaction were common molecular and cellular functions.

The retrieval of common molecular and cellular functions and/or pathways by the two approaches (metaanalysis vs. individual experiments) confirms the statistical power of the meta-analysis and its complementary to the FDR correction with regard to the pruning of false positives. Furthermore, the identification of novel affected biological functions and pathways further shows the added value of the meta-analysis approach.

\section{Comparison between $E$. coli and S. aureus infections}

To better evaluate the pathogen-specific characteristics, we further compared the responses to infection with $E$. coli (experiment 1A) or $S$. aureus (experiments $1 \mathrm{~B}$ and $1 \mathrm{C}$ ) in the cattle host. We excluded the $S$. uberis data (experiment 2) as we had only one single time point $\{9\}$ available.

We used the PAMR package to identify the genes which were most dissimilar in terms of their activation in response to the two different pathogens. Of the retained 34 most dissimilar genes, 21 were down-regulated by $E$. coli infection and up-regulated by $S$. aureus infection, while 13 showed the opposite trend (Table 3 ).

This list of dissimilar genes was further analyzed with IPA to identify altered biological functions and networks. The 5 most significant molecular and cellular functions identified were cellular development, cellular growth and proliferation, cellular function and maintenance, cell death, and lipid metabolism [Additional file 7]. Both cell death and lipid metabolism were previously found to be among the 5 most significant molecular functions altered in proteins of cows infected with either E. coli or S. aureus [39]. The IPA network called "antigen presentation, inflammatory response, cell-to-cell signaling and interaction" was the most significantly represented by the list of dissimilar genes. Of the 34 genes, 9 are included in this network: BTG1, CD74, CSDA, FKBP5, IGFBP5, GLUL, HSPD1, LCN2, and PHB. $I G F B P 5$ and $C D 74$ were up-regulated after $E$. coli infection and down-regulated after $S$. aureus infection, while the others showed the opposite trend (Table 3).

Pathogen-dependent differences in the time kinetics of induced receptors and defense molecules (e.g. TLR2, TLR4, IL-8, TNF, and NFkB), as measured by real-time PCR, have been reported between $E$. coli and $S$. aureus $[27,55]$. Although none of these defense genes were in the list of the 34 most dissimilar genes, our results were in general agreement with these findings as we found that the majority of genes with opposed regulation were associated with immune response and mainly belonged to the antigen presentation, inflammatory response, cellto-cell signaling and interaction network.

These findings suggest that, at least at the transcriptomic level, these two pathogens cause distinct forms of mastitis infection by the differential modulation of genes belonging to similar molecular pathways and biological functions.

\section{Comparisons of the 4 lists (I - IV) of affected genes}

In order to have an accurate global view of the lists of genes belonging to the 4 different responses to mastitis infection (I to IV), we drew a Venn diagram (Figure 3) that provides a graphical representation of the number 
Table 3 Dissimilar genes between $E$. coli and S. aureus infections in cattle

\begin{tabular}{|c|c|c|c|}
\hline Gene & Gene Name & $\begin{array}{l}\text { E. coli shrunken } \\
\text { centroid }\end{array}$ & $\begin{array}{l}\text { S. aureus shrunken } \\
\text { centroid }\end{array}$ \\
\hline$A B C G 2$ & ATP-binding cassette, sub-family G WHITE, member 2 & -1.007 & 0.671 \\
\hline IDH1 & Isocitrate dehydrogenase $1 \mathrm{NADP}+$, soluble & -0.929 & 0.619 \\
\hline AGPAT1 & 1-acylglycerol-3-phosphate O-acyltransferase 1 lysophosphatidic acid acyltransferase, alpha & -0.894 & 0.596 \\
\hline PCGF1 & Polycomb group ring finger 1 & -0.795 & 0.53 \\
\hline GALNTL4 & UDP-N-acetyl-alpha-D-galactosamine:polypeptide N-acetylgalactosaminyltransferase-like 4 & -0.52 & 0.346 \\
\hline CD74 & CD74 molecule, major histocompatibility complex, class II invariant chain & -0.496 & 0.33 \\
\hline TMEM164 & Transmembrane protein 164 & -0.42 & 0.28 \\
\hline RHOF & Ras homolog gene family, member $F$ & -0.391 & 0.261 \\
\hline MFSD4 & Major facilitator superfamily domain containing 4 & -0.263 & 0.175 \\
\hline DGCR2 & DiGeorge syndrome critical region gene 2 & -0.217 & 0.145 \\
\hline FEZ1 & Fasciculation and elongation protein zeta 1 zygin I & -0.204 & 0.136 \\
\hline PAOX & Polyamine oxidase exo-N4-amino & -0.154 & 0.103 \\
\hline PMEPA1 & Prostate transmembrane protein, androgen induced 1 & -0.106 & 0.07 \\
\hline$H I G D 1 B$ & HIG1 hypoxia inducible domain family, member 1B & -0.134 & 0.089 \\
\hline DNAJC12 & DnaJ Hsp40 homolog, subfamily C, member 12 & -0.132 & 0.088 \\
\hline VWF & Von Willebrand factor & -0.131 & 0.088 \\
\hline KIAA1467 & KIAA1467 & -0.131 & 0.087 \\
\hline SENP2 & SUMO1/sentrin/SMT3 specific peptidase 2 & -0.068 & 0.046 \\
\hline IGFBP5 & Insulin-like growth factor binding protein 5 & -0.06 & 0.04 \\
\hline SCP2 & Sterol carrier protein 2 & -0.018 & 0.012 \\
\hline NPAL2 & NIPA-like domain containing 2 & -0.009 & 0.006 \\
\hline$\angle R R N 3$ & Leucine rich repeat neuronal 3 & 0.732 & -0.488 \\
\hline FKBP5 & FK506 binding protein 5 & 0.7 & -0.466 \\
\hline SLC38A7 & Solute carrier family 38, member 7 & 0.641 & -0.427 \\
\hline HSPD1 & Heat shock 60 kDa protein 1 chaperonin & 0.56 & -0.373 \\
\hline GLUL & Glutamate-ammonia ligase glutamine synthetase & 0.352 & -0.235 \\
\hline CSDA & Cold shock domain protein $A$ & 0.174 & -0.116 \\
\hline INO80E & INO80 complex subunit E & 0.142 & -0.095 \\
\hline SAT1 & Spermidine/spermine N1-acetyltransferase 1 & 0.118 & -0.079 \\
\hline PHB & Prohibitin & 0.075 & -0.05 \\
\hline STAT3 & Signal transducer and activator of transcription 3 acute-phase response factor & 0.061 & -0.04 \\
\hline MAX & MYC associated factor $X$ & 0.051 & -0.034 \\
\hline BTG1 & B-cell translocation gene 1, anti-proliferative & 0.033 & -0.022 \\
\hline LCN2 & Lipocalin 2 & 0.024 & -0.016 \\
\hline
\end{tabular}

List of the 34 most dissimilarly regulated genes identified with the PAMR software, showing opposite fold change responses during E. coli and S. aureus infections in cattle in vivo (experiment $1 \mathrm{~A}, \mathrm{~B}$, and C). For each gene, the PAMR shrunken centroid values (using a threshold parameter of 3.77) for the E. coli and the $S$. aureus experiments are reported. Twenty-one of the listed genes were up-regulated during infection with $S$. aureus, while 13 were up-regulated during $E$. coli infection.

of affected genes, as inferred by Pointillist, that are in common, exclusive, or at the various intersections between 2 or 3 lists. The corresponding gene lists with the gene names can be found in [Additional file 8]. Interestingly, we identified a family of antimicrobial genes (S100A11, S100A12, S100A8, and S100A9) that were affected in all but the early stage response. This finding was in line with a recent study in cattle, where microarray analysis using Affymetrix gene chip revealed that these genes were differentially expressed after $24 \mathrm{~h}$, but not 6 h, of E. coli infection [52].

However, the vast majority of the listed genes have not previously been reported to be implicated in the mastitis infection process. Of particular interest are those genes, a total of 92 [Additional file 8], in common between the 4 (overall, early stage, late stage, and cattlespecific) responses to mastitis (Figure 3), providing possible clues for valuable candidate biomarkers.

\section{Altered pathways and biological functions related to the 92 genes in common for all 4 responses}

The 3 most affected canonical pathways underlying these 92 common genes [Additional file 2] were polyamine regulation, protein ubiquitination, and molecular mechanisms of cancer. The pathways LXR/RXR activation and factors promoting cardiogenesis in vertebrates 


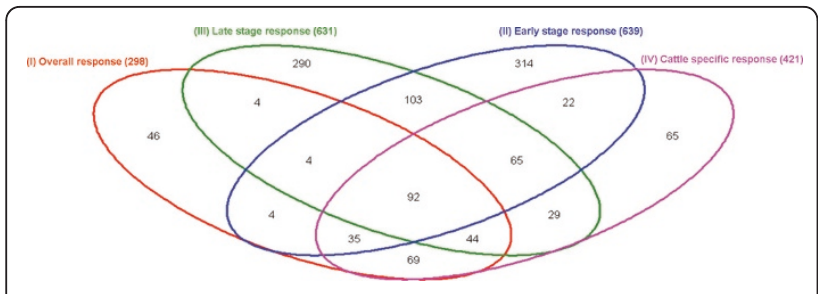

Figure 3 Venn diagram showing the number of common and combination-specific affected genes. Venn diagram illustrating the number of significantly affected genes in common (92) and distinct for the four meta-analysis combinations (red: 298 genes of the overall response, green: 631 genes of the late stage response, blue: 639 genes of the early stage response, and pink: 421 genes of the cattle-specific response). The lists of corresponding genes can be found in [Additional file 8].

only approached statistical significance $(0.05<\mathrm{p}<0.1)$. Altered molecular and cellular functions identified by IPA [Additional file 3] showed general cell related functions (cellular function and maintenance, cellular growth and proliferation, cellular movement, and nucleic acid metabolism) as well as, once again, lipid metabolism.

\section{Conclusions}

To the best of our knowledge this study is the first that statistically combines heterogeneous microarray data realized with different ruminant host species and infected with different mastitis-causing pathogens. The results reinforced previous findings but also revealed several novel themes, including the involvement of genes and pathways that were not identified in individual studies.

Among the 5 most significant molecular and cellular functions common to all 4 gene lists of differential responses to mastitis were cell death, cellular movement, and cellular growth and proliferation, i.e. functions which are intrinsic to general disease response. This indicates that the described procedure of meta-analysis could cope well with the high heterogeneity of the biological systems and the different microarrays used. Indeed, this was confirmed by the analysis of the reduced list of 92 genes in common to all lists that also identified cellular growth and proliferation and cellular movement as being altered.

The results show that protein ubiquitination and polyamine regulation, two pathways involved in immune response modulation and represented by different individual genes, possibly represent a common biological manifestation during mastitis infection in different biological systems. Furthermore, strong complementarities between the early stage and late stages of infection was found, showing a prominence of metabolic and stress signals in the early stage and of the immune response related to the lipid metabolism in the late stage, Both mechanisms were apparently triggered by a small number of genes, including XBP1 and SREBF1. The cattlespecific response showed an intensification of the immune and inflammatory responses through $\mathrm{T}$ lymphocyte involvement. Furthermore, we found several strands of evidence suggesting a correlation between immune response and lipid metabolism as a hallmark of the response of ruminants against mastitis infection.

Overall, the reported meta-analysis approach successfully combined heterogeneous data sets and extracted information of value from individual microarray studies of limited size and statistical power. As such, it provides a global transcriptomic reference which could be useful for the development of novel therapeutics and vaccines for mastitis in ruminants. Furthermore, these data and methodology provide an interesting proof of principle for future studies combining information from diverse sources.

\section{Methods}

\section{Collection and analysis of microarray data}

Microarray data on host responses to infection by mastitis-causing pathogens for various challenge systems were selected to represent contrasting pathogens, hosts, challenge systems (i.e. host tissues or cells, in vivo and in vitro), sample sizes, time period of observations, microarrays, and signs of infection (summarized in Table 1 with the corresponding references). The experiments were performed with the approval of appropriate ethics committees. Experiment 1 was conducted under the approval of the ethics committee of the regional government in Hannover, Germany (No 509.6-42502-03/678). Experiment 2 was approved by the ethical committee of the Central Veterinary Institute of Wageningen UR in accordance with the Dutch law on animal experiments (registered under number 870.474.05.00.01). Experiment 3 only involved bleeding bovine heifers for $300 \mathrm{ml}$ blood. According to Norwegian legislation no special approval was necessary. The experiments 4 and 6 were, according to the Italian legislation, successfully notified and hence approved by the Italian ethics committee. In experiment 5 ewes were sacrificed in accordance with local regulations (agreement number 31-2010-67) and the study was approved by the INRA animal ethics committee (France).

Spot analysis and quality control of the microarray data for all experiments were done with BlueFuse version 3.1 (BlueGnome, Cambridge, UK; http://www.cambridgebluegnome.com), except for experiment 5 (dendritic cells, DCs) in sheep which was analyzed using SAS ANOVA. The Bioconductor package Limma (Linear Models for Microarray Analysis) in R was used for data normalization and differential expression analyses, comparing gene expression at given times after infection 
with gene expression in non-infected controls. For each of these analyses p-values were assigned to all genes, indicating the probability that the observed difference in expression occurred by chance. These p-values were then used for the meta-analysis using the Pointillist software. Fold change differences were also calculated and used for specific analyses, in particular for the cattlespecific response.

\section{Meta-analysis procedures}

The 6 datasets from the three ruminant species were obtained from different bovine microarrays, including cDNA arrays (ARK-genomics and National Bovine Functional Genomics Consortium, NBFGC) and commercial oligonucleotide arrays containing 43,768 unique probes (CombiMatrix CustomArray ${ }^{\circledR}$, CombiMatrix Corporation, Seattle, WA, USA) (Table 1).

The preprocessing of the ARK-genomics array data entailed two noteworthy clone ID mapping steps to obtain clone ID consistency throughout all ARK-genomics datasets: the mapping of the clone IDs of a $17 \mathrm{~K}$ array design onto those of a $20 \mathrm{~K}$ array design and the mapping of child clone IDs onto the corresponding master clone IDs. The p-values of all groups of master and child clones were averaged, to obtain one value for each master clone ID. Further, the control probes were left out of the meta-analysis, as this was also done for the data stemming from the other microarray platforms.

To compare the probes of the ARK-genomics arrays to those of goat experiment 4 (NBFGC bovine cDNA array, [57]) or goat experiment 6 (CombiMatrix array), a blast comparison between all the spotted sequences was performed. A contiguous perfect match segment of 100 nucleotides (nt) was considered sufficient for probes to be similar. This is a conservative threshold, since perfect matching segments of $30 \mathrm{nt}$ can already cause crosshybridization in cDNA microarray experiments [58] and since according to the Baldino formula [59] $100 \mathrm{nt}$ long segments under standard conditions can still hybridize while having a mismatch of $15 \%$. A total of 8,302 and 8,293 probes, respectively, were found to be in common.

After evaluation of different meta-analysis methods and programs, an appropriate statistical program called Pointillist (http://magnet.systemsbiology.net/software/ Pointillist; $[20,21])$ that allowed us to account for the relevant experimental differences and the heterogeneity of the datasets, was used to perform meta-analysis. Pointillist is a general-purpose tool that predicts whether system elements are affected by a system perturbation, by integrating different items of evidence of that perturbation. The evidence contains $\mathrm{p}$-values for each addressed element, can address different subsets of the system's elements and may be derived from any type of experiment. In our case the elements are the microarray clones and the items of evidence are the differential expression analyses carried out for selected time points. In a first step Pointillist classifies elements as "affected", if for any of the items of evidence the quantile value of the element's p-value is below a chosen threshold alpha (0.05 in our case). "Combined effective significances (CES)" are calculated by weighting, normalizing, transforming, and combining the element's specific p-values into one single element significance using a Fisher-like transformation (with the Pointillist option called "power") and by finally smoothing the distribution of these significances using a smoothed Gaussian kernel density function. In each step the overlap between the "combined effective significance" distribution for the group of affected and for the group of non-affected elements is iteratively minimized. This process, which is an alternative method to the FDR-adjustment commonly used in the analysis of single data sets, ultimately minimizes the number of false positives and false negatives. The weights used during the transforming operation are also calculated for each item of evidence in each iteration step by comparing the current classification in affected and non-affected elements with the p-value distribution of that evidence. Every Pointillist run contained a row for each probe having a p-value in at least two of the included time points. A special scenario was followed for the final 3-step Pointillist run of the overall analysis, in which the probes common to the cattle and sheep were combined with the probes used in the goat experiments.

\section{Probe annotation}

A probe annotation was performed to transform the microarray probe IDs into gene IDs recognized by Ingenuity Pathways Knowledge Base (IPA, Ingenuity Systems, Mountain View, CA; http://www.ingenuity.com). The annotation started from the probes' EMBL or GenBank accession: the ARK-genomic and CombiMatrix arrays contained probes with references to EMBL accessions in the arrays' GAL files, while the NBFGC array probe names contained references to Genbank accessions. Several probes spotted on the arrays did not have any accession reference due to the incomplete information available at the time of microarray construction. In case these had protein-like names, they were presented as such to IPA. Otherwise they had to be discarded from further analyses. For the probes having an accession reference, an automated stepwise annotation was performed with an in-house script based on sigReannot [60] which took advantage of the recent re-annotation of the cattle genome [61]. A first step verified whether the probes were known to be situated within genomic regions of genes in the Ensembl bovine database (version 52). If this was not the case, in a second step the 
extracted EMBL or GenBank sequences were mapped to the Ensembl bovine transcripts with a blast cutoff threshold of e-10. In a final step, still unmatched clones were mapped to the complete RefSeq RNA database at NCBI http://www.ncbi.nlm.nih.gov/projects/RefSeq with a blast cutoff threshold of e-5. When the probe coordinates were found to overlap with more than one gene or when blasting against the Ensembl bovine database returned multiple blast hits with a difference in nucleotide coverage between the first and second best hit of $<10 \%$, the probe was discarded. For multiple blast hits against the Ensembl bovine database with higher coverage differences, the best covering BLAST hit was nevertheless retained. Next, the Ensembl gene IDs were themselves mapped onto entries from several other target gene databases. For a mapped entry to become the final probe annotation fed to IPA, it obviously had to be recognized by IPA. An arbitrary preference order of the target gene databases was used when screening for IPA recognition: human HGNC, human Entrez, RefSeq Protein, RefSeq RNA, bovine Unigene and bovine Entrez. Also, preference was given to one-to-one mappings.

\section{Assignment of affected genes to pathways, networks and biological functions}

Each gene symbol of the affected genes identified with Pointillist was mapped to its corresponding gene object in the Ingenuity Pathways Knowledge Base. Feeding the aforementioned lists of affected genes as input to the IPA library, significantly associated canonical pathways, biological functions and networks were identified in order to gain biological context and understanding.

Affected biological functions included the sub-groups "Diseases and disorders", "Physiological system development and function" and "Molecular and cellular functions". While the two first sub-groups are highly linked to human diseases and physiology and IPA mainly relies on human data, the third sub-group is relatively general and was better suited for our meta-analysis data. In order to summarize and reduce the vast amount of data generated, which is reported in [Additional files 2 and $3]$, we focused and discussed in the text the 5 most affected pathways and the 5 most affected biological functions belonging to the sub-group "Molecular and cellular functions".

The found IPA library items were ranked based on significance of association with the input list of genes. For the canonical pathways this significance was determined based on two parameters: (a) ratio of the number of genes from the input data set that map to the canonical pathway divided by the total number of genes of that pathway and (b) p-values calculated using Fischer's exact test determining the probability that the association is explained by chance alone. For the biological functions and networks the significance was linked to the p-value only, calculated by right-tailed Fisher's exact test. The pvalues for the network analysis take into account the number of affected genes in the network and the size of the network. Identified networks are presented as a graph indicating the molecular relationships between genes/gene products. Genes are represented as nodes, and the biological relationship between two nodes is represented as an edge (line). All edges are supported by at least one reference from the literature, from a textbook, or from information stored in the IPA Knowledge Base. The intensity of the node color indicates the degree of up- (red) or down-regulation (green). Genes in uncolored nodes were not identified as differentially expressed in the experiment. The intrinsic size of networks, functions and pathways, used in the calculation of the significance of association, depend on the chosen IPA gene "universe". We did not change the IPA default "universe", basically containing all genes and endogenous chemicals of the IPA library.

The additional IPA function called "building pathway" was used to graphically show the relationship and interactions between genes belonging to significantly affected IPA gene networks during the early stage response to mastitis, and to connect all lipogenic genes identified during the late stage response.

\section{Venn diagram and heat map building, and visualization of fold change variations in different cattle experiments} The Venn diagram was built using $\mathrm{R}$ script overLapper. R http://faculty.ucr.edu/ tgirke/Documents/R_BioCond/ My_R_Scripts/overLapper.R.

The heat map was constructed with the "heatmap" function of the R package "stats". The R package MaSigPro [53] was used to visualize the magnitude of fold change expressions during the time course of the different cattle microarray experiments $1 \mathrm{~A}$ \{time points 1,2 , $3\}, 1 \mathrm{~B}$ \{time points $4,5,6\}, 1 \mathrm{C}$ time points 7,8$\}, 2$ $\{$ time point 9$\}$, and 3 time points 10,11$\}$.

\section{Fold change dissimilarities between $E$. coli and S. aureus infections in cattle in vivo}

The $\mathrm{R}$ package PAMR was used to detect dissimilarities among fold change responses to E. coli and S. aureus pathogen infections in vivo in cattle (experiment $1 \mathrm{~A}, 1 \mathrm{~B}$, and $1 \mathrm{C}$, Table 1). The PAMR algorithm performs an expression-profile based sample class prediction [62]. In a first step, average within-class expression profiles, so called "centroids", are calculated for all sample classes. In a next step, these centroids are shrunken, shifting the average within-class expression of each gene towards the gene's overall expression average, and taking a gene out of the centroid when its within-class expression average coincides with the overall one. The extent of 
gene expression shrinkage is proportional to the gene's within-class standard deviation, and is also determined by the chosen "threshold" or "shrinkage" parameter. The higher the threshold, the fewer genes that are retained in the class shrunken centroids and the more dissimilar they are. Finally, samples can then be classified by mapping them to the shrunken centroid that is nearest to the sample's expression profile. Here we used PAMR to construct shrunken centroids of the two classes of the E. coli and S. aureus infected samples. For a range of threshold parameters, PAMR evaluated the classification accuracy and the size of the resulting shrunken centroids. Out of the threshold parameters yielding the highest classification accuracy, we selected the lowest threshold parameter that brought the shrunken centroid's size below an arbitrarily chosen limit of 50 dissimilar genes. In this specific case, a threshold parameter of 3.77 was selected, and this resulted in the 34 most dissimilar genes being retained in the resulting shrunken centroids. These dissimilar genes were further examined with IPA.

\section{Additional material}

Additional file 1: Lists of affected genes during different responses to mastitis infection. Complete lists of affected genes and corresponding "Combined Effective Significances (CES)" identified with pointillist for the 4 main responses to mastitis (I) overall response, (II) early stage response, (III) late stage response, (IV) cattle-specific response, as well as the two additional time dependent responses $(V)$ early specific and (VI) late specific.

Additional file 2: Lists of all affected canonical pathways and corresponding affected genes. Complete lists of affected canonical pathways $(p<0.05)$ and corresponding affected genes identified with IPA for the meta-analysis combinations (I) overall response, (II) early stage response, (III) late stage response, (IV) cattle-specific response, (V) early specific response and (VI) late specific response, as well as for the common affected genes between the 4 meta-analysis responses (I) to (IV) (Figure 3, n= 92). The identified canonical pathways are listed from the lowest to the highest $p$-value. An asterisk indicates that the pathway approached statistical significance $(0.05<p<0.1)$.

Additional file 3: Lists of all affected biological functions and corresponding affected genes. Complete lists of all affected biological functions $(p<0.05)$ and corresponding affected genes identified with IPA for the meta-analysis combinations (I) overall response, (II) early stage response, (III) late stage response, (IV) cattle-specific response, (V) early specific response and (VI) late specific response, as well as for the common affected genes between the 4 meta-analysis responses (I) to (IV) (Figure 3, $n=92$ ). The biological functions include all the sub-groups "Diseases and disorders", "Physiological system development and function" and "Molecular and cellular functions" and are listed from the lowest to the highest p-value. The five most affected molecular and cellular functions, which are discussed in the text, are in bold.

Additional file 4: Affected sub-functions of lipid metabolism during different responses to mastitis infection. Five most significant subfunctions of lipid metabolism that are altered during (I) overall, (II) early stage, (III) late stage, and (IV) cattle-specific responses. The results were obtained by IPA using the lists of significantly affected genes for each specific response. The sub-functions of the lipid metabolism are listed from the lowest to the highest $\mathrm{p}$-value, and are reported with the involved genes.
Additional file 5: Supplemental Figure S1 - Relationship between $X B P 1$ and additional affected genes during the early stage response to mastitis. Gene network showing the connections, as identified with the IPA option "building pathways", between the gene XBP1 and other affected genes during (II) early stage response to mastitis infection. $\mathbf{A}$. XBP1 is related and linked to several other affected genes. $\mathbf{B}$. XBP1 is directly linked to the genes COPZ1, DDOST, KDELR2, KDELR3, RPN1, SEC23B, SEC24D, SEC61A1, and SRPR, as well as to genes of the proteasome and the MHC Class II complex. Supplemental Figure S2 Relationship between SREBF1 and additional affected genes during the late stage response to mastitis. Gene network showing the connections, as identified with the IPA option "building pathways", between affected genes involved in lipid metabolism during (III) late stage response to mastitis infection. The gene SREBF1 seems to play an important role and is directly linked to other affected genes (violet colour), i.e. TRAF3IP3, CD36, SCD, SOD1, IDH1, THRB, RETN, PMVK, DBI, UCP2, HBS1, SC4MOL, and CYP27A1. Supplemental Figure S3 - Venn diagram showing the number of common and experiment-specific affected genes between (IV) cattlespecific response and the individual experiments $1 \mathrm{~A}$ time point $\{3\}$ and 2 time point $\{9\}$. Venn diagram illustrating the number of significantly affected genes in common (25) and distinct for the (IV) cattle-specific response (red: 421 genes), experiment 1A time point \{3\} (green: 745 genes), and experiment 2 time point $\{9\}$ (blue: 55 genes). The lists of corresponding genes can be found in [Additional file 6]. The list of experiments and time points can be found in Table 1 and the list of meta-analysis combinations in Table 2.

Additional file 6: Lists of affected genes that are distinct or in common between (IV) cattle-specific response, experiment 1A time point $\{3\}$, and experiment 2 time point $\{9\}$. Complete lists of affected genes corresponding to the Venn diagram [Additional file 5:

Supplemental Figure S3], including genes that are distinct or in common at the intersections between (IV) cattle-specific response, experiment $1 \mathrm{~A}$ time point $\{3\}$, and experiment 2 time point $\{9\}$. The list of experiments and time points can be found in Table 1 and the list of meta-analysis combinations in Table 2.

Additional file 7: Affected molecular and cellular functions of the most dissimilar genes between $E$. coli and $S$. aureus. Five most significant molecular and cellular functions identified with IPA using the 34 most dissimilar genes between E. coli and S. aureus infections in cattle in vivo (experiment $1 \mathrm{~A}, 1 \mathrm{~B}$, and $1 \mathrm{C}$ ), as found with the PAMR software (Table 3). The identified molecular and cellular functions are listed from the lowest to the highest p-value, and are reported with the involved genes.

Additional file 8: Lists of affected genes that are distinct or in common between the 4 main responses to mastitis infection. Complete lists of affected genes corresponding to the Venn diagram in Figure 3 , including genes that are distinct or in common at the intersections between the 4 different responses (I) overall, (II) early stage, (III) late stage, and (IV) cattle-specific.

\section{Acknowledgements}

The authors are grateful to Dr. DJ de Koning, The Roslin Institute and R(D) SVS, University of Edinburgh, for introducing the Pointillist program and providing helpful advice and opinions at various stages of the study. This project was financed by FP6-EADGENE (European Animal Disease Genomics Network of Excellence, EU Contract No. FOOD-CT-2004-506416). The authors declare no competing financial interests.

\section{Author details}

'Parco Tecnologico Padano - CERSA, Via Einstein, 26900 Lodi, Italy. ${ }^{2}$ The Roslin Institute and R(D)SVS, Division of Genetics and Genomics, Roslin, Midlothian, University of Edinburgh, EH25 9RG, UK. ${ }^{3}$ INRA/AgroParisTech, UMR1236 Génétique et Diversité Animales, F-78352 Jouy en Josas, France. ${ }^{4}$ INRA, Sigenae UR875 Biométrie et Intelligence Artificielle, BP 52627, F-31326 Castanet-Tolosan Cedex, France. ${ }^{5}$ INRA, Sigenae UR83 Recherches Avicoles, F37380 Nouzilly, France. ${ }^{6}$ Leibniz Institute for Farm Animal Biology (FBN), Molecular Biology Research Unit, Wilhelm-Stahl-Allee 2, D-18196 
Dummerstorf, Germany. ${ }^{7}$ Clinic for Ruminants, Ludwig-Maximilians University, Munich, Germany. ${ }^{8}$ Central Veterinary Institute of Wageningen UR, P.O. Box 65, $8200 \mathrm{AB}$, Lelystad, The Netherlands. 'Wageningen UR Livestock Research, Animal Breeding and Genomics Centre, P.O. Box 65, 8200 AB, Lelystad, The Netherlands. ${ }^{10}$ Department of Basic Sciences and Aquatic Medicine, Norwegian School of Veterinary Science, P.O. Box 8146 Dep, NO-0033 Oslo, Norway. ${ }^{11}$ Università degli Studi di Milano, Department of Veterinary Pathology, Hygiene and Public Health, via Celoria 10, 20133 Milan, Italy. ${ }^{12}$ Istituto di Biologia e Biotecnologia Agraria, Consiglio Nazionale delle Ricerche, Milan, Italy. ${ }^{13}$ INRA-ENVT, UMR1225, Interactions Hôtes Agents Pathogènes, F-31300 Toulouse, France. ${ }^{14}$ INRA, UR631, Station d'Amélioration Génétique des Animaux, F-31326 Castanet-Tolosan, France. ${ }^{15}$ Department of Clinical Studies, School of Veterinary Medicine, University of Pennsylvania, Philadelphia, PA 19104, USA. ${ }^{16}$ Quality Milk Production Services, Cornell University, Ithaca, New York, USA. ${ }^{17}$ INRA, UMR 1313 de Génétique Animale et Biologie Intégrative, Jouy-en-Josas, France.

\section{Authors' contributions}

$\mathrm{SG}, \mathrm{BB}$, and GS wrote the paper, collated the microarray data, and performed the meta-analysis. SCB helped to conceive the meta-analysis project, supervised the meta-analysis, helped to write the paper and helped to collate the microarray data. DW performed analysis of single microarray experiments and supervised the meta-analysis. MHP coordinated the entire EADGENE project, helped collecting and sharing the microarray data. CC and CK developed bioinformatic tools used to produce the gene annotations for this study. HMS coordinated the work of the EADGENE's groups working on mastitis and developed microarray experiment 1, in particular arranged for the animal infection experiments, sample collection, and initial RNA preparations. WP conducted the animal infections, recorded the zootechnical/health parameters throughout the experiments, and prepared all the tissues. $\mathrm{KJ}$ did all the hybridizations and data analysis of experiment 1. EJG developed in conjunction with HMS experiment 1 and helped in sample preparation and data analysis. AdG performed the experimental infection with S. uberis and performed microarray experiment 2. HES initiated the mastitis work at the central veterinary institute, wrote the S. uberis project, and designed the experimental infection of experiment 2. MAS was the contact person for EADGENE at the Animals Sciences Group and was closely involved in the initiation of the operational genomics work package within the network. 10 was involved in the planning of the NSVS microarray experiment 3, partly participated in the practical work, and helped with the analysis of the data and the manuscript writing. GMB conducted the microarray experiment 3 in the laboratory (biological samples preparation and hybridization). PM, GP, BC, and PC organized the experiments, collected the samples, performed the experimental infections with $\mathrm{S}$. aureus in goat, and analyzed the microarray data of experiments 4 and 6. MDC prepared and edited the data of experiment 6 . EF conducted the microarray experiment 5 in the laboratory (biological samples preparation and hybridization). GF planned the experimental design of microarray experiment 5 in sheep. RR developed the design of microarray experiment 5 and did statistical analysis of the data. EG helped to conceive the metaanalysis project, coordinated the overall project and helped in writing this manuscript. All authors read and approved the final manuscript.

Received: 3 December 2010 Accepted: 11 May 2011 Published: 11 May 2011

\section{References}

1. Davies G, Genini S, Bishop SC, Giuffra E: An assessment of opportunities to dissect host genetic variation in resistance to infectious diseases in livestock. Animal 2009, 3:415-436.

2. Hedges LV, Olkin I: Statistical Methods for Meta-Analysis Orlando, FL: Academic Press; 1985.

3. Stangl DK, Berry DA: Meta-Analysis in Medicine and Health Policy New York, NY: Marcel Dekker; 2000.

4. Rhodes DR, Barrette TR, Rubin MA, Ghosh D, Chinnaiyan AM: Meta-analysis of microarrays: interstudy validation of gene expression profiles reveals pathway dysregulation in prostate cancer. Cancer Res 2002, 62(15):4427-4433.

5. Choi JK, Yu U, Kim S, Yoo OJ: Combining multiple microarray studies and modeling interstudy variation. Bioinformatics 2003, 19(Suppl 1):i84-90.
6. Choi JK, Choi JY, Kim DG, Choi DW, Kim BY, Lee KH, Yeom YI, Yoo HS, Yoo OJ, Kim S: Integrative analysis of multiple gene expression profiles applied to liver cancer study. FEBS Lett 2004, 565(1-3):93-100.

7. Rhodes DR, Yu J, Shanker K, Deshpande N, Varambally R, Ghosh D, Barrette T, Pandey A, Chinnaiyan AM: Large-scale meta-analysis of cancer microarray data identifies common transcriptional profiles of neoplastic transformation and progression. Proc Natl Acad Sci USA 2004, 101(25):9309-9314.

8. de Magalhaes JP, Curado J, Church GM: Meta-analysis of age-related gene expression profiles identifies common signatures of aging. Bioinformatics 2009, 25(7):875-881.

9. Greco D, Somervuo P, Di Lieto A, Raitila T, Nitsch L, Castren E, Auvinen P: Physiology, pathology and relatedness of human tissues from gene expression meta-analysis. PLoS One 2008, 3(4):e1880.

10. Jelier R, 't Hoen PA, Sterrenburg E, den Dunnen JT, van Ommen GJ, Kors JA, Mons B: Literature-aided meta-analysis of microarray data: a compendium study on muscle development and disease. BMC Bioinformatics 2008, 9:291.

11. Pihur V, Datta S, Datta S: Finding common genes in multiple cancer types through meta-analysis of microarray experiments: a rank aggregation approach. Genomics 2008, 92(6):400-403.

12. Pennings $\mathrm{JL}$, Kimman $T G$, Janssen R: Identification of a common gene expression response in different lung inflammatory diseases in rodents and macaques. PLOS One 2008, 3(7):e2596.

13. Sohal D, Yeatts A, Ye K, Pellagatti A, Zhou L, Pahanish P, Mo Y, Bhagat T, Mariadason J, Boultwood J, Melnick A, Greally J, Verma A: Meta-analysis of microarray studies reveals a novel hematopoietic progenitor cell signature and demonstrates feasibility of inter-platform data integration. PLoS One 2008, 3(8):e2965.

14. Gyorffy B, Schafer R: Meta-analysis of gene expression profiles related to relapse-free survival in 1,079 breast cancer patients. Breast Cancer Res Treat 2009, 118(3):433-441.

15. Edwards $Y J$, Bryson $\mathrm{K}$, Jones DT: A meta-analysis of microarray gene expression in mouse stem cells: redefining stemness. PLoS One 2008, 3(7):e2712.

16. Hedges LV, Pigott TD: The power of statistical tests in meta-analysis. Psychol Methods 2001, 6(3):203-217.

17. Hedges LV, Pigott TD: The power of statistical tests for moderators in meta-analysis. Psychol Methods 2004, 9(4):426-445.

18. Loughin TM: A systematic comparison of methods for combining pvalues from independent tests. Comput Stat Data Anal 2004, 47(3):467-485.

19. Marot G, Foulley JL, Mayer CD, Jaffrezic F: Moderated effect size and Pvalue combinations for microarray meta-analyses. Bioinformatics 2009, 25(20):2692-2699.

20. Hwang D, Rust AG, Ramsey S, Smith JJ, Leslie DM, Weston AD, de Atauri P, Aitchison JD, Hood L, Siegel AF, Bolouri H: A data integration methodology for systems biology. Proc Natl Acad Sci USA 2005, 102(48):17296-17301

21. Hwang D, Smith JJ, Leslie DM, Weston AD, Rust AG, Ramsey S, de Atauri P,

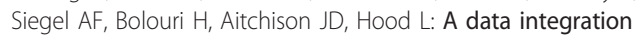
methodology for systems biology: experimental verification. Proc Natl Acad Sci USA 2005, 102(48):17302-17307.

22. Moreau Y, Aerts S, De Moor B, De Strooper B, Dabrowski M: Comparison and meta-analysis of microarray data: from the bench to the computer desk. Trends Genet 2003, 19(10):570-577.

23. Fierro AC, Vandenbussche F, Engelen K, Van de Peer Y, Marchal K: Meta Analysis of Gene Expression Data within and Across Species. Curr Genomics 2008, 9(8):525-534.

24. Nau GJ, Richmond JF, Schlesinger A, Jennings EG, Lander ES, Young RA: Human macrophage activation programs induced by bacterial pathogens. Proc Natl Acad Sci USA 2002, 99(3):1503-1508.

25. Huang Q, Liu D, Majewski P, Schulte LC, Korn JM, Young RA, Lander ES, Hacohen N: The plasticity of dendritic cell responses to pathogens and their components. Science 2001, 294(5543):870-875.

26. Jenner RG, Young RA: Insights into host responses against pathogens from transcriptional profiling. Nat Rev Microbiol 2005, 3(4):281-294.

27. Petzl W, Zerbe H, Gunther J, Yang W, Seyfert HM, Nurnberg G, Schuberth HJ: Escherichia coli, but not Staphylococcus aureus triggers an early increased expression of factors contributing to the innate immune defense in the udder of the cow. Vet Res 2008, 39(2):18. 
28. Liu F, Walters KJ: Multitasking with ubiquitin through multivalent interactions. Trends Biochem Sci 2010, 35(6):352-360

29. Ciechanover $A$ : The ubiquitin-proteasome pathway: on protein death and cell life. EMBO J 1998, 17(24):7151-7160.

30. Rytkonen A, Holden DW: Bacterial interference of ubiquitination and deubiquitination. Cell Host Microbe 2007, 1(1):13-22.

31. Ramadori G, Christ B: Cytokines and the hepatic acute-phase response. Semin Liver Dis 1999, 19(2):141-155.

32. Carroll JA, Reuter RR, Chase CC Jr, Coleman SW, Riley DG, Spiers DE, Arthington JD, Galyean ML: Profile of the bovine acute-phase response following an intravenous bolus-dose lipopolysaccharide challenge. Innate Immun 2009, 15(2):81-89.

33. Suojala L, Orro T, Jarvinen $H$, Saatsi J, Pyorala $S$ : Acute phase response in two consecutive experimentally induced $\mathrm{E}$ coli intramammary infections in dairy cows. Acta Vet Scand 2008, 50:18.

34. Bendelac A, Teyton L, Savage PB: Lipid presentation by CD1: the short and the long lipid story. Nat Immunol 2002, 3(5):421-422.

35. Gomez-Lechon MJ: Oncostatin M: signal transduction and biological activity. Life Sci 1999, 65(20):2019-2030.

36. Hava DL, Brigl M, van den Elzen P, Zajonc DM, Wilson IA, Brenner MB: CD assembly and the formation of CD1-antigen complexes. Curr Opin Immunol 2005, 17(1):88-94.

37. Moyes KM, Drackley JK, Morin DE, Bionaz M, Rodriguez-Zas SL, Everts RE, Lewin HA, Loor JJ: Gene network and pathway analysis of bovine mammary tissue challenged with Streptococcus uberis reveals induction of cell proliferation and inhibition of PPARgamma signaling as potential mechanism for the negative relationships between immune response and lipid metabolism. BMC Genomics 2009, 10:542.

38. Moyes KM, Drackley JK, Morin DE, Rodriguez-Zas SL, Everts RE, Lewin HA, Loor JJ: Predisposition of cows to mastitis in non-infected mammary glands: effects of dietary-induced negative energy balance during midlactation on immune-related genes. Funct Integr Genomics 2011 11(1):151-156

39. Ibeagha-Awemu EM, Ibeagha AE, Messier S, Zhao X: Proteomics, genomics, and pathway analyses of Escherichia coli and Staphylococcus aureus infected milk whey reveal molecular pathways and networks involved in mastitis. J Proteome Res 2010, 9(9):4604-4619.

40. Imtiyaz HZ, Simon MC: Hypoxia-inducible factors as essential regulators of inflammation. Curr Top Microbiol Immunol 2010, 810:105-120.

41. Lin W, Harding HP, Ron D, Popko B: Endoplasmic reticulum stress modulates the response of myelinating oligodendrocytes to the immune cytokine interferon-gamma. J Cell Biol 2005, 169(4):603-612.

42. Hasko G, Kuhel DG, Marton A, Nemeth ZH, Deitch EA, Szabo C: Spermine differentially regulates the production of interleukin-12 p40 and interleukin-10 and suppresses the release of the T helper 1 cytokine interferon-gamma. Shock 2000, 14(2):144-149.

43. Swanson K, Gorodetsky S, Good L, Davis S, Musgrave D, Stelwagen K, Farr V, Molenaar A: Expression of a beta-defensin mRNA, lingual antimicrobial peptide, in bovine mammary epithelial tissue is induced by mastitis. Infect Immun 2004, 72(12):7311-7314.

44. Lutzow YC, Donaldson L, Gray CP, Vuocolo T, Pearson RD, Reverter A, Byrne KA, Sheehy PA, Windon R, Tellam RL: Identification of immune genes and proteins involved in the response of bovine mammary tissue to Staphylococcus aureus infection. BMC Vet Res 2008, 4:18.

45. Schroder M, Kaufman RJ: The mammalian unfolded protein response. Annu Rev Biochem 2005, 74:739-789.

46. Norata GD, Ongari M, Uboldi P, Pellegatta F, Catapano AL: Liver X receptor and retinoic $X$ receptor agonists modulate the expression of genes involved in lipid metabolism in human endothelial cells. Int $\mathrm{J} \mathrm{Mol}$ Med 2005, 16(4):717-722.

47. Morris DG, Waters SM, McCarthy SD, Patton J, Earley B, Fitzpatrick R, Murphy JJ, Diskin MG, Kenny DA, Brass A, Wathes DC: Pleiotropic effects of negative energy balance in the postpartum dairy cow on splenic gene expression: repercussions for innate and adaptive immunity. Physiol Genomics 2009, 39(1):28-37.

48. Iwakoshi NN, Lee AH, Glimcher LH: The X-box binding protein-1 transcription factor is required for plasma cell differentiation and the unfolded protein response. Immunol Rev 2003, 194:29-38.

49. Zeng L, Liu YP, Sha H, Chen H, Qi L, Smith JA: XBP-1 Couples Endoplasmic Reticulum Stress to Augmented IFN-\{beta\} Induction via a cis-Acting Enhancer in Macrophages. J Immunol 2010, 185(4):2324-2330.
50. Sriburi R, Bommiasamy H, Buldak GL, Robbins GR, Frank M, Jackowski S, Brewer JW: Coordinate regulation of phospholipid biosynthesis and secretory pathway gene expression in XBP-1(S)-induced endoplasmic reticulum biogenesis. J Biol Chem 2007, 282(10):7024-7034.

51. Sauer K, Cooke MP: Regulation of immune cell development through soluble inositol-1,3,4,5-tetrakisphosphate. Nat Rev Immunol 2010, 10(4):257-271.

52. Mitterhuemer S, Petzl W, Krebs S, Mehne D, Klanner A, Wolf E, Zerbe H, Blum $\mathrm{H}$ : Escherichia coli infection induces distinct local and systemic transcriptome responses in the mammary gland. BMC Genomics 2010, 11:138.

53. Conesa A, Nueda MJ, Ferrer A, Talon M: maSigPro: a method to identify significantly differential expression profiles in time-course microarray experiments. Bioinformatics 2006, 22(9):1096-1102.

54. Burvenich C, Van Merris V, Mehrzad J, Diez-Fraile A, Duchateau L: Severity of $\mathrm{E}$ coli mastitis is mainly determined by cow factors. Vet Res 2003, 34(5):521-564.

55. Yang W, Zerbe H, Petzl W, Brunner RM, Gunther J, Draing C, von Aulock S, Schuberth HJ, Seyfert HM: Bovine TLR2 and TLR4 properly transduce signals from Staphylococcus aureus and E. coli, but $\mathrm{S}$. aureus fails to both activate NF-kappaB in mammary epithelial cells and to quickly induce TNFalpha and interleukin-8 (CXCL8) expression in the udder. $\mathrm{Mol}$ Immunol 2008, 45(5):1385-1397.

56. Benjamini Y, Hochberg Y: Controlling the False Discovery Rate: A Practical and Powerful Approach to Multiple Testing. Journal of the Royal Statistical Society Series B (Methodological) 1995, 57(1):289-300.

57. Suchyta SP, Sipkovsky S, Kruska R, Jeffers A, McNulty A, Coussens MJ, Tempelman RJ, Halgren RG, Saama PM, Bauman DE, Boisclair YR, Burton JL, Collier RJ, DePeters EJ, Ferris TA, Lucy MC, McGuire MA, Medrano JF, Overton TR, Smith TP, Smith GW, Sonstegard TS, Spain JN, Spiers DE, Yao J, Coussens PM: Development and testing of a high-density cDNA microarray resource for cattle. Physiol Genomics 2003, 15(2):158-164.

58. Talla E, Tekaia F, Brino L, Dujon B: A novel design of whole-genome microarray probes for Saccharomyces cerevisiae which minimizes crosshybridization. BMC Genomics 2003, 4(1):38.

59. Baldino F Jr, Chesselet MF, Lewis ME: High-resolution in situ hybridization histochemistry. Methods Enzymol 1989, 168:761-777.

60. Casel P, Moreews F, Lagarrigue S, Klopp C: sigReannot: an oligo-set reannotation pipeline based on similarities with the Ensembl transcripts and Unigene clusters. BMC Proc 2009, 3(Suppl 4):S3.

61. Bovine Genome Sequencing and Analysis Consortium, Elsik CG, Tellam RL, Worley KC, Gibbs RA, Muzny DM, Weinstock GM, Adelson DL, Eichler EE, Elnitski L, Guigo R, Hamernik DL, Kappes SM, Lewin HA, Lynn DJ, Nicholas FW, Reymond A, Rijnkels M, Skow LC, Zdobnov EM, Schook L, Womack J, Alioto T, Antonarakis SE, Astashyn A, Chapple CE, Chen HC, Chrast J, Camara F, Ermolaeva O, Henrichsen CN, Hlavina W, Kapustin Y, Kiryutin B, Kitts P, Kokocinski F, Landrum M, Maglott D, Pruitt K, Sapojnikov V, Searle SM, Solovyev V, Souvorov A, Ucla C, Wyss C, Anzola JM, Gerlach D, Elhaik E, Graur D, Reese JT, Edgar RC, McEwan JC, Payne GM, Raison JM, Junier T, Kriventseva EV, Eyras E, Plass M, Donthu R, Larkin DM, Reecy J, Yang MQ, Chen L, Cheng Z, Chitko-McKown CG, Liu GE, Matukumalli LK, Song J, Zhu B, Bradley DG, Brinkman FS, Lau LP, Whiteside MD, Walker A, Wheeler T, Casey T, German JB, Lemay DG, Magbool NJ, Molenaar AJ, Seo S, Stothard P, Baldwin CL, Baxter R, Brinkmeyer-Langford CL, Brown WC, Childers CP, Connelley T, Ellis SA, Fritz K, Glass EJ, Herzig CT, livanainen A, Lahmers KK, Bennett AK, Dickens CM, Gilbert JG, Hagen DE, Salih H, Aerts J, Caetano AR, Dalrymple B, Garcia JF, Gill CA, Hiendleder SG, Memili E, Spurlock D, Williams JL Jr, Alexander L, Brownstein MJ, Guan L, Holt RA, Jones SJ, Marra MA, Moore R, Moore SS, Roberts A, Taniguchi M, Waterman RC, Chacko J, Chandrabose MM, Cree A, Dao MD, Dinh HH, Gabisi RA, Hines S, Hume J, Jhangiani SN, Joshi V, Kovar CL, Lewis LR, Liu YS, Lopez J, Morgan MB, Nguyen NB, Okwuonu GO, Ruiz SJ, Santibanez J, Wright RA, Buhay C, Ding Y, Dugan-Rocha S, Herdandez J, Holder M, Sabo A, Egan A, Goodell J, Wilczek-Boney K, Fowler GR, Hitchens ME, Lozado RJ, Moen C, Steffen D, Warren JT, Zhang J, Chiu R, Schein JE, Durbin KJ, Havlak P, Jiang H, Liu Y, Qin X, Ren Y, Shen Y, Song H, Bell SN, Davis C, Johnson AJ, Lee S, Nazareth LV, Patel BM, Pu LL, Vattathil S, Williams RL, Curry S, Hamilton C, Sodergren E, Wheeler DA, Barris W, Bennett GL, Eggen A, Green RD, Harhay GP, Hobbs M, Jann O, Keele JW, Kent MP, Lien S, McKay SD, McWilliam S, Ratnakumar A, Schnabel RD, Smith T, Snelling WM, 
Sonstegard TS, Stone RT, Sugimoto Y, Takasuga A, Taylor JF, Van Tassell CP, Macneil MD, Abatepaulo AR, Abbey CA, Ahola V, Almeida IG, Amadio AF, Anatriello E, Bahadue SM, Biase FH, Boldt CR, Carroll JA, Carvalho WA, Cervelatti EP, Chacko E, Chapin JE, Cheng Y, Choi J, Colley AJ, de Campos TA, De Donato M, Santos IK, de Oliveira CJ, Deobald H, Devinoy E, Donohue KE, Dovc P, Eberlein A, Fitzsimmons CJ, Franzin AM, Garcia GR, Genini S, Gladney CJ, Grant JR, Greaser ML, Green JA, Hadsell DL, Hakimov HA, Halgren R, Harrow JL, Hart EA, Hastings N, Hernandez M, Hu ZL, Ingham A, Iso-Touru T, Jamis C, Jensen K, Kapetis D, Kerr T, Khalil SS, Khatib H, Kolbehdari D, Kumar CG, Kumar D, Leach R, Lee JC, Li C, Logan KM, Malinverni R, Marques E, Martin WF, Martins NF, Maruyama SR, Mazza R, McLean KL, Medrano JF, Moreno BT, More DD, Muntean CT, Nandakumar HP, Nogueira MF, Olsaker I, Pant SD, Panzitta F, Pastor RC, Poli MA, Poslusny N, Rachagani S, Ranganathan S, Razpet A, Riggs PK, Rincon G, Rodriguez-Osorio N, Rodriguez-Zas SL, Romero NE, Rosenwald A, Sando L, Schmutz SM, Shen L, Sherman L, Southey BR, Lutzow YS, Sweedler JV, Tammen I, Telugu BP, Urbanski JM, Utsunomiya YT, Verschoor CP, Waardenberg AJ, Wang Z, Ward R, Weikard R, Welsh TH Jr, White SN, Wilming LG, Wunderlich KR, Yang J, Zhao FQ: The genome sequence of taurine cattle: a window to ruminant biology and evolution. Science 2009, 324(5926):522-528.

62. Tibshirani R, Hastie T, Narasimhan B, Chu G: Diagnosis of multiple cancer types by shrunken centroids of gene expression. Proc Natl Acad Sci USA 2002, 99(10):6567-6572.

63. Jaffrezic F, de Koning DJ, Boettcher PJ, Bonnet A, Buitenhuis B, Closset R, Dejean S, Delmas C, Detilleux JC, Dovc P, Duval M, Foulley JL, Hedegaard J, Hornshoj H, Hulsegge I, Janss L, Jensen K, Jiang L, Lavric M, Le Cao KA, Lund MS, Malinverni R, Marot G, Nie H, Petzl W, Pool MH, Robert-Granie C, San Cristobal M, van Schothorst EM, Schuberth HJ, Sorensen P, Stella A, Tosser-Klopp G, Waddington D, Watson M, Yang W, Zerbe H, Seyfert HM: Analysis of the real EADGENE data set: comparison of methods and guidelines for data normalisation and selection of differentially expressed genes (open access publication). Genet Sel Evol 2007, 39(6):633-650

64. de Koning DJ, Jaffrezic F, Lund MS, Watson M, Channing C, Hulsegge I, Pool MH, Buitenhuis B, Hedegaard J, Hornshoj H, Jiang L, Sorensen P, Marot G, Delmas C, Le Cao KA, San Cristobal M, Baron MD, Malinverni R, Stella A, Brunner RM, Seyfert HM, Jensen K, Mouzaki D, Waddington D, Jimenez-Marin A, Perez-Alegre M, Perez-Reinado E, Closset R, Detilleux JC, Dovc P, Lavric M, Nie H, Janss L: The EADGENE Microarray Data Analysis Workshop (open access publication). Genet Sel Evol 2007, 39(6):621-631.

65. Pisoni G, Castiglioni B, Stella A, Boettcher PJ, Genini S, Giuffra E, Moroni P. Microarray analysis of gene expression of milk leukocytes in healthy goats. Vet Res Commun 2008, 32(Suppl 1):S219-21.

66. Pisoni G, Moroni P, Genini S, Stella A, Boettcher PJ, Cremonesi P, Scaccabarozzi L, Giuffra E, Castiglioni B: Differentially expressed genes associated with Staphylococcus aureus mastitis in dairy goats. Vet Immunol Immunopathol 2010, 135(3-4):208-217.

doi:10.1186/1471-2164-12-225

Cite this article as: Genini et al: Strengthening insights into host responses to mastitis infection in ruminants by combining heterogeneous microarray data sources. BMC Genomics 2011 12:225.

\section{Submit your next manuscript to BioMed Central and take full advantage of:}

- Convenient online submission

- Thorough peer review

- No space constraints or color figure charges

- Immediate publication on acceptance

- Inclusion in PubMed, CAS, Scopus and Google Scholar

- Research which is freely available for redistribution

Submit your manuscript at www.biomedcentral.com/submit
C Biomed Central 